\title{
O OLHAR DO PROFESSOR UNIVERSITÁRIO SOBRE A AUTONOMIA DO ALUNO EM AMBIENTES DE TECNOLOGIAS DE APRENDIZAGEM
}

\author{
Wladia Bessa da CRUZ \\ Márcio Luis Ferreira NASCIMENTO ${ }^{\text {ii }}$ \\ Maria Aparecida Pereira VIANA ${ }^{\mathrm{iii}}$
}

\begin{abstract}
RESUMO
Este trabalho consiste numa investigação sobre o olhar dos professores do ensino superior de duas instituições públicas na cidade de Maceió em relação à autonomia do aluno. Objetiva investigar como o professor universitário percebe a autonomia do aluno no processo de aprendizagem, visando ao uso de novas metodologias, das tecnologias da informação e comunicação (TIC) e da integração com todos os participantes do curso. A verificação da existência dessa autonomia do aluno é um processo complexo, pois envolve vários elementos pessoais como: iniciativa, organização, motivação, interação com as partes envolvidas; e externos como: estrutura organizacional, currículo, metodologia utilizada, relação pedagógica, bem como o formato do sistema educacional. A metodologia adotada fundamenta-se na pesquisa qualitativa com abordagem descritiva. A partir da análise dos dados na perspectiva do professor, foram sugeridas mudanças no currículo, em novas metodologias como aprendizagem baseada em problemas, o uso do ensino híbrido e da sala de aula invertida. Eles também citaram que as tecnologias podem ser usadas para ajudar nesse processo de aprendizagem, desde que os alunos tenham maturidade, responsabilidade e disciplina para usá-las, pois as mesmas podem também dispersá-los. Existe a necessidade de um aprofundamento do tema, pois pode-se entender que, embora tenhamos níveis de autonomia, não nos é possível sermos totalmente autônomos nesse processo de aprendizagem.
\end{abstract}

PALAVRAS-CHAVE: Professor; Autonomia aluno; Ensino Superior; Processo de aprendizagem.

\section{THE LOOK OF THE UNIVERSITY TEACHER ON STUDENT AUTONOMY IN LEARNINGTÍTULO TECHNOLOGY ENVIROMENTS}

\begin{abstract}
This work consists of an investigation about the perception of higher education professors from two public institutions in the city of Maceio, in relation to the student's autonomy. It focuses to investigate how the university professor perceives the student's autonomy during the learning process, aiming to

${ }^{\text {i }}$ Doutoranda do Programa de Engenharia Industrial da Universidade Federal da Bahia. É professora do Instituto Federal de Alagoas com atuação no ensino técnico e graduação de informática. E-mail: wladiabessa@ gmail.com. ii Físico pela Universidade de São Paulo (USP), com Mestrado em Física do Estado Sólido também pela USP. Doutor em Ciência e Engenharia dos Materiais pela Universidade Federal de São Carlos (UFSCar). Atualmente, é professor da Escola Politécnica da Universidade Federal da Bahia (UFBA). E-mail: mlfn@ ufba.br.

iii Doutora em Educação: Currículo (PUC-SP,2013) com estágio científico avançado de Pós-Doutorado na Universidade do Minho, Portugal. É professora do Centro de Educação da Universidade Federal de Alagoas com atuação na graduação e na gestão do curso de Pedagogia. E-mail: vianamota@gmail.com.
\end{abstract}


use new methodologies, information and communication technologies (ICT), and integration with all participants. The verification of student's autonomy existence is a complex process. It involves several personal elements, such as: initiative, organization, motivation, interaction with involved parties; and external elements: organizational structure, curriculum, methodology used, pedagogical relation, as well as the format of the educational system. The methodology used is based on the qualitative research with a descriptive approach. From the data analysis of the professor's perspective, changes to the curriculum were suggested, and new methodologies such as problem-based learning, the use of hybrid teaching, and inverted classroom were proven to be the most efficient. It was also mentioned that technology could also be used to help in the learning process, as long as the students have the maturity, responsibility, and discipline necessary to use it, as it could also disperse them. There is a need of deeper research into the topic, because it is possible to conclude that, although students have levels of autonomy, they cannot be totally autonomous in the learning process.

KEYWORDS: Teacher; Student autonomy; Higher education; Learning process.

\title{
LA MIRADA DEL PROFESORUNIVERSITARIO SOBRE LA AUTONOMÍA DEL ALUMNO EM AMBINETES DE TECNOLÍGIAS DE APRENDIJAZE
}

\begin{abstract}
RESUMEN
Este trabajo consiste en una investigación sobre la percepción de profesores de la enseñanza superior de dos instituciones públicas en la ciudad de Maceió con respecto a la autonomía del alumno. Tiene por objetivo investigar como el profesor universitario percibe la autonomía del discente en el proceso de aprendizaje, teniendo como propósito el uso de nuevas metodologías, de las tecnologías de la información y comunicación (TIC) y de la integración entre todos los participantes. La verificación de la existencia de dicha autonomía del alumno es un proceso complejo, pues involucra varios elementos personales, tales como: iniciativa, organización, motivación, interacción, con las partes implicadas; y externos tales como: estructura de organización, currículo, metodología utilizada, relación pedagógica, así como el formato del sistema educativo. La metodología adoptada se fundamenta en la investigación cualitativa con enfoque descriptivo. A partir del análisis de los datos en la perspectiva del profesor, se han sugeridos cambios en el currículo, en nuevas metodologías como el aprendizaje basado en problemas, el uso de la enseñanza híbrida y del aula de clase invertido. Ellos también han citado que las tecnologías pueden ser usadas para ayudar en ese proceso de aprendizaje, desde que los alumnos tengan madurez, responsabilidad y disciplina para usarlas, pues ellas pueden también despistarlos. Hay la necesidad de una profundización del tema ya que se puede comprender que, aunque tengamos niveles de autonomía, no nos es posible ser totalmente autónomos en ese proceso de aprendizaje.
\end{abstract}

PALAVRAS CLAVE: Profesor; Autonomía alumno; Enseñanza Superior; Proceso de Aprendizaje.

\section{INTRODUÇÃO}

Aprender comporta a união do conhecido e do desconhecido (MORIN, 2005; MATURANA, 2001), possibilitando que, para todo ato de conhecer, surja um mundo, havendo nesse processo uma modificação não apenas do indivíduo, mas de todo o sistema (e seu 
entorno). Para Piaget (1996), o processo de aprendizagem do indivíduo se dá com interações e perturbações do conhecimento em seu meio, considerando, como critério, a idade do indivíduo relacionada ao contexto.

As escolas e universidades atuais foram concebidas há mais de um século para serem exatamente o oposto das necessidades de aprendizagem de hoje, que necessitam de diferenciação e customização. Segundo Horn e Staker (2015), cada estudante aprende em um ritmo diferente, pois cada um tem sua "memória de trabalho" ${ }^{1 "}$ e "memória de longo prazo" diferentes.

Para Vieira (1998, p. 23)

Na sociedade atual, em constante evolução, cada vez mais heterogênea sob todos os pontos de vista, onde a capacidade de refletir criticamente, de resolver problemas, de efetuar escolhas e tomar decisões é quase condição de sobrevivência, a autonomia assume um lugar imprescindível na vida de cada um, e a escola não pode alhear-se desse fato.

Pensar sobre a ação do professor com uso das tecnologias, o processo de aprendizagem, e a autonomia do aluno nos diversos ambientes é um desafio para as propostas acadêmicas contemporâneas, pois o formato das escolas e universidade é o mesmo há muito tempo. Em primeiro lugar, porque o assunto em análise requer reflexão sobre a concepção de produção de conhecimento na qual, historicamente, a escola e a universidade pautaram-se, sendo, portanto, necessariamente, uma reflexão epistemológica; e em segundo, porque põe em xeque a própria prática do professor, considerada inquestionável pela cultura acadêmica.

Segundo Viana (2013, p. 14), “nas sociedades contemporâneas, as rápidas transformações no mundo do trabalho, bem como o avanço tecnológico que configura a sociedade virtual e os meios de informação, vêm incidindo fortemente na educação, levando a um aumento dos desafios para torná-la uma conquista democrática efetiva”. Diante destes fatos as instituições ensino tem um questionamento sobre qual o seu papel ante as transformações econômicas, políticas, sociais e culturais do mundo atual.

O desafio que o professor tem pela frente é a construção do conhecimento gerado através da busca e da pesquisa. O processo de produção de conhecimento é permanente e dinâmico, assumindo um papel fundamental, ao lado dos processos de organização e de distribuição da informação. O ensino superior necessita atender às novas demandas e, nesse processo, os professores ocupam um papel estratégico. A dinâmica do mundo moderno impõe, 
em todas as áreas, profissionais questionadores e dinâmicos que ultrapassem os limites da simples execução. As capacidades de pensar e decidir são essenciais para a assimilação de mudanças e para o confronto com desafios que surgem todos os dias, tendo a autonomia presente nesse processo.

Pensando em todas essas habilidades que precisam ser desenvolvidas no aluno de hoje, as questões da pesquisa são: como o professor vê a autonomia do aluno? Como o professor pode colaborar com o desenvolvimento da autonomia do aluno?

Para a realização deste estudo, foram selecionadas respostas de questionários aplicados a um grupo de professores das áreas de humanas e exatas, de duas universidades públicas de Alagoas.

Este estudo tem como objetivo investigar como o professor percebe a autonomia do aluno nos ambientes de aprendizagem. Nesse sentido, este trabalho foi embasado pelos teóricos: Vygotsky (1984); Piaget (1996); Siemens (2005); Moran (2012,2015); Knowles (1990), entre outros. A relevância desta pesquisa é que ela possa trazer algumas orientações para os professores colaborarem no desenvolvimento da autonomia do aluno nos ambientes de aprendizagem.

Acredita-se que o aluno deve ser um sujeito capaz de trabalhar colaborativamente, de resolver problemas, de superar dificuldades, de poder estabelecer mudanças no seu meio social, sendo-lhe necessário desenvolver essas competências ao longo da sua vida acadêmica.

Para Botelho e Fialho (2009, p. 2)

As universidades, em especial, vêm sofrendo grandes alterações nos últimos vinte e cinco anos, principalmente por força das mudanças sociais e econômicas, criando pressões e tensões que não aconteciam no passado de forma tão evidente e intensa. Massificação, heterogeneidade dos alunos, novas culturas de qualidade, mudanças no mundo produtivo e do trabalho, internacionalização dos estudos superiores, novas orientações para a formação e redução de fundos são alguns dos fatores que têm repercutido na forma como as instituições de ensino superior organizam os seus recursos e estabelecem a oferta formativa.

É nesse contexto de transformações que as universidades têm de se reorganizar de forma a ajustar as ofertas formativas às múltiplas exigências do mundo atual, renovando as práticas dos professores no sentido da formação de cidadãos capazes de se integrarem, participando dos ambientes sociais e profissionais cada vez mais complexos e exigentes, numa lógica de educação e formação ao longo da vida. 
Segundo Delors (2003, p. 89) [..] "a educação deve organizar-se em torno de quatro aprendizagens fundamentais que, ao longo de toda a vida, serão de algum modo, para cada indivíduo, os pilares do conhecimento : aprender a conhecer, isto é adquirir os instrumentos da compreensão; aprender a fazer, para poder agir sobre o meio envolvente; aprender a viver juntos, a fim de participar e cooperar com os outros em todas as atividades humanas; aprender $a$ ser, via essencial que integra as três precedentes".

Hoje, com as diversas Tecnologias de Informação e Comunicação (TIC) e os vários ambientes de aprendizagem, presenciais, a distância e híbridos, o professor precisa fazer uso de todos esses recursos nesse processo de aprendizagem, pois os alunos atuais estão muito mais conectados do que há 20 anos. Segundo Viana et al. (2015, p. 3), “a focar na aprendizagem mais participativa, integrada e integradora, com momentos presenciais e online, em que docentes e discentes podem interagir virtualmente e, também, manter vínculos pessoais e afetivos". Todas as atividades que hoje envolvem as tecnologias exigem uma capacidade de autonomia dos indivíduos, incluindo, nesse contexto, as diversas formações, como a educação a distância, que pressupõem essa autonomia.

Sobre o aluno autônomo, Preti (2005) apud Lima et al. (2010, p.2), “o aluno/aprendente precisa desenvolver atitudes que promovam a interaprendizagem e a pesquisa, estando sempre disposto e motivado a empreender ações de modo a viabilizar seu acesso ao conhecimento". Este autor explica que, "principalmente na Educação a Distância $(\mathrm{EaD})$, o aluno precisa ser incentivado a desenvolver sua autonomia para garantir a condução e efetivação de sua aprendizagem, haja vista que não dispõe do acompanhamento do professor no presencial e direto para realizar seus estudos”. (LIMA et al., 2010, p.4)

Segundo Almeida e Silva (2011, p. 4), “a disseminação e o uso de tecnologias digitais, marcadamente dos computadores e da internet, favoreceram o desenvolvimento de uma cultura de uso das mídias e, por conseguinte, de uma configuração social pautada num modelo digital de pensar, criar, produzir, comunicar, aprender - viver. As tecnologias móveis e a Web 2.0, principalmente, são responsáveis por grande parte dessa nova configuração social do mundo que se entrelaça com o espaço digital”. Também evoluímos para a Web 3.0, onde os conteúdos online estarão organizados de forma semântica, personalizados para cada usuário. Já a Web 4.0 é a "Web Movel”, a qual, vai conectar todos os dispositivos dos mundos real e virtual em tempo real. E por último a Web 5.0, conhecida como "Web Emocional”, será sobre a interação 
(emocional) entre humanos e computadores, a qual está em fase de desenvolvimento. Para Almeida e Silva (ibid., p.4), o uso das TIC permite estabelecer relacionamentos e conexões entre distintos contextos de práticas sociais, aninhados em diversos suportes digitais (textos, imagens, vídeos, áudios, hipertextos, representações tridimensionais) interativos, que propiciam aos inter-atores a escolha dos elementos (nós) e caminhos a seguir, criando as próprias narrativas, ou seja, produzindo uma nova obra e tornando-se coautor da obra original (MANOVICH, 2005).

\section{TEORIAS DA APRENDIZAGEM}

As teorias da aprendizagem são as referências básicas quando se deseja entender e melhorar o processo de ensino e aprendizagem. Através dessas teorias, torna-se mais fácil entender algumas situações, como também identificar variáveis que estão presentes nesse processo.

Foram tomadas como aporte teórico as teorias de Lev Vygotsky (1896 - 1934), Jean Piaget (1896 - 1980) e George Siemens ( $n$. 1970), assim como novas abordagens para as teorias no tocante à Andragogia e à Heutagogia para uma melhor compreensão e fundamentação das ações do professor e dos alunos nesses ambientes.

As pesquisas de Piaget, segundo Caetano (2010, p. 1), "tinham como objetivo definir, a partir da perspectiva da biologia, como o sujeito passaria de um conhecimento menor anterior para um nível de maior conhecimento”. Para Piaget (1997), o construtivismo é o processo de aprendizagem do indivíduo de acordo com interações e perturbações do conhecimento em seu meio, e tendo como critérios a idade do indivíduo e seu contexto.

Piaget (1996), na sua teoria, definiu o estágio operatório formal que é a entrada do ser na fase adulta em termos cognitivos. Nessa fase, o adulto estabelece o pensamento lógico e dedutivo, permitindo a experimentação mental e o raciocínio sobre as hipóteses. Segundo Saravali (2005, p.2), o sujeito tem a capacidade de estabelecer relações, de combinar diferentes e até infinitas perspectivas da mesma questão, de pensar sobre o próprio pensamento. Essas conquistas marcantes do desenvolvimento modificam tremendamente as condições de interação do sujeito com o meio; e é esse tipo de pensamento que será exigido do aluno do ensino superior. Segundo Saravali 
O sujeito tem a capacidade de estabelecer relações, de combinar diferentes e até infinitas perspectivas da mesma questão, de pensar sobre o próprio pensamento. Essas conquistas marcantes do desenvolvimento modificam tremendamente as condições de interação do sujeito com o meio; e é esse tipo de pensamento que será exigido do aluno do ensino superior (SARAVALI, 2005, p. 244).

Acredita-se que o aluno quando chega no ensino superior seja capaz de refletir, pensar, analisar a sociedade, trabalhar com conceitos abstratos e organizar formas para a execução do trabalho.

A teoria de Vygotsky fornece uma profunda compreensão do ensino e da aprendizagem que reflete a complexidade dos contextos sociais e culturais no aluno moderno. Segundo Verenikina (2010, p. 3), Vygotsky (1978) afirmou que "a mente humana é construída por meio das interações com o mundo e é um atributo da relação entre sujeito e objeto. A consciência não é redutível ao comportamento nem separada dele, mas é um atributo da organização da prática”. A atividade é o processo que organiza o comportamento. Vygotsky(1978) introduziu o conceito de atividade mediada, que são ações que envolvem o uso de meios externos para atingir um objetivo. Verinkina (ibid.p.3), “de acordo com Vygotsky, a "boa aprendizagem” ocorre na zona de desenvolvimento proximal (ZDP)".

Assim, a ZDP é a distância entre o que uma pessoa pode fazer com e sem ajuda. É definida como a diferença entre o nível real de desenvolvimento, conforme determinado pela resolução de problemas independentes e o nível mais alto de desenvolvimento potencial, conforme determinado através da resolução de problemas sob orientação ou em colaboração com pares mais capazes (VYGOTSKY, 1978). Isso significa que o aprendizado na ZDP referese a uma série de atividades que a pessoa não consegue realizar sozinha, mas pode executá-las com a ajuda de um professor ou de colegas mais capazes. Para Verenikina (ibidem, p. 5), "a teoria da atividade adota o princípio básico da teoria de Vygotsky de que as ferramentas ocupam um papel mediador na reação humana e interação com o mundo". As ferramentas podem ser: externas como artefatos, instrumentos e máquinas; ou internas, como leis, sinais, procedimentos, métodos e linguagem.

Com a inserção das TIC, houve uma grande mudança na educação superior através de cursos presenciais, a distância e semipresenciais. Discute-se bastante o papel do professor e do aluno nesse novo contexto, levando a um confronto com as exigências de absorver novas 
demandas e métodos de ensino, entretanto não têm sido discutidos, com a devida preocupação, os suportes tecnológicos.

Escudero e Trillo (2017, p. 82)

Concluem provisoriamente que existe uma prevalência de um modelo de formação mais centrado no como da docência e nos recursos TIC, do que na fundamentação psicossocial das práticas; a outra é a quase absoluta omissão nos assuntos que dizem respeito às dimensões organizativas do fazer docente, do trabalho colaborativo com outros colegas, e da indagação reflexiva sobre o ensino e a aprendizagem.

O conectivismo surgiu nesse contexto com George Siemens (n. 1970) e Stephen Downes (n. 1959) como uma nova abordagem educacional, segundo a qual o conhecimento está distribuído numa rede de conexões e que, desse modo, a aprendizagem consiste na capacidade de edificar essas redes e circular nelas, desenvolvendo, assim a capacidade de refletir, decidir e partilhar. Assim sendo, o aluno pode conduzir sua aprendizagem de forma mais autônoma, sem a presença do professor. Siemens (2005, p.1) "aponta o Behaviorismo, o Cognitivismo e o Construtivismo como sendo as teorias mais usadas na criação de ambientes instrucionais. Contudo, essas teorias foram desenvolvidas em um tempo em que não existia o impacto das tecnologias". O Conectivismo visa responder às necessidades dos alunos do século XXI e às novas realidades introduzidas pelo desenvolvimento tecnológico, visando à importância da aprendizagem informal, e mostrando a grande variedade de meios e formas de aprendizagem.

Muitos ainda não aceitam o conectivismo enquanto teoria de aprendizagem, embora traga reflexões a respeito das tendências desse processo no século XXI. As pessoas estão conectadas em sites de relacionamentos, em redes sociais, em blogs, revistas online, nos quais o conhecimento e as informações são distribuídos a qualquer tempo e espaço.

Hoje, com todo esse aparato tecnológico, existe a necessidade de se conhecer novos modelos educacionais, pois o que se conhece e se aplica há muitos anos é a Pedagogia. Há novas práticas educacionais emergentes na era da informação, como a Andragogia e a Heutagogia, que estão relacionadas ao processo de aprendizagem de adultos, tanto na modalidade presencial como a distância.

Em ambas as modalidades, precisa-se considerar as especificidades dos alunos que, na maioria das vezes, são adultos, e têm suas particularidades para aprender que não são 
consideradas na Pedagogia. Lindeman (1926, p. 8-9), um dos maiores estudiosos sobre educação de adultos, afirmou que:

[...] a educação de adulto será através de situações e não de disciplinas. Nosso sistema acadêmico cresce em ordem inversa: disciplinas e professores constituem o centro educacional. Na educação convencional é exigido do estudante ajustar-se ao currículo estabelecido; na educação de adulto o currículo é construído em função da necessidade do estudante. Todo adulto se vê envolvido com situações específicas de trabalho, de lazer, de família, da comunidade, etc. - situações essas que exigem ajustamentos. O adulto começa nesse ponto. As matérias (disciplinas) só devem ser introduzidas quando necessárias. Textos e professores têm um papel secundário nesse tipo de educação; eles devem dar a máxima importância ao aprendiz.

Assim, nosso sistema acadêmico está indo em direção contrária à forma de aprendizagem do adulto, necessitando, portanto, de modelos educacionais que acompanhem esse processo de aprendizagem, sendo importante conhecer um pouco mais da Andragogia.

A Andragogia é a arte e ciência de auxiliar o adulto a aprender. Difundida nos Estados Unidos por Malcolm Knowles (1913 - 1997), é uma aprendizagem voltada para o adulto, no qual se leva em consideração a sua experiência de vida. É autodirigida, mais autônoma, voltada para a resolução de problemas, na qual o professor tem um papel de mediador. Bellan (2005, p. 55) esclarece que:

[...] quando o professor decide articular seus papéis de aprendizagem pela ótica da andragogia, sua postura precisa ser revista e transformada num agente facilitador com visão das diferentes formas de aprendizagem [...]. Esse novo professor/facilitador deve apresentar informações e técnicas através de técnicas de ensino e criar um ambiente adequado para a aprendizagem.

Segundo Knowles (1990) apud Coelho et al. (2016, p.7), “entende-se por aprendizagem autônoma como um processo de ensino e aprendizagem centrado no aluno, cujas experiências são usadas como mecanismo que faz com que o professor se torne recurso do aprendiz". $\mathrm{Na}$ verdade, o professor vai prover os recursos para esse processo, e o aluno vai fazer suas escolhas de como, o que e quando aprender.

A Andragogia dá importância à assimilação de novos conhecimentos para o desenvolvimento de novas habilidades, exigência de um mundo em constante mutação, mas levando em consideração a experiência do aluno adulto.

Knowles (2005) traz que a aprendizagem de adultos é baseada em suposições diferentes da pedagogia, algumas delas são: são motivados a aprender quando experimentam necessidades 
e interesses que a aprendizagem trará satisfação; a orientação para aprendizagem é centrada na vida; a metodologia central é a análise de experiência; os adultos têm uma necessidade de serem autodirecionados; diferenças individuais entre pessoas aumentam com a idade, portanto, deve se fazer a provisão para diferenças de estilo, tempo, lugar e ritmo de aprendizagem.

Corroboram-se as ideias de Vygotsky e Piaget no se que refere à importância da interação do ser com o meio, considerando que os alunos aprendem muito mais quando são ativos, questionadores, tomam decisões e trazem suas experiências para sala de aula. Para Siemens (2005, p.7), “o conectivismo apresenta um modelo de aprendizado que reconhece as mudanças tectônicas na sociedade, sendo a aprendizagem não mais uma atividade interna individualista. A maneira como as pessoas trabalham e funcionam é alterada quando novas ferramentas são utilizadas".

\subsection{As TICS como ferramentas nos ambientes de aprendizagem}

As principais TICs provocaram mudanças por seu impacto significativo sobre a cultura e reorientaram as perspectivas sociais, econômicas, científicas e políticas. Em 1873, James Clerk Maxwell (1831 - 1879) publicou o tratado sobre eletricidade e magnetismo que constituiu um importante avanço e abriu espaço para muitos equipamentos de comunicação e informação, partindo dos primeiros equipamentos como a impressão tipográfica de Johannes Gutenberg (1394 - 1468), aparelho de telégrafo, telefone, TV, computadores até chegar na rede mundial de computadores. A sociedade evolui desde os primórdios com essas tecnologias e, hoje, cada dia mais a sociedade depende delas.

Para Musacchio (2014, p.1), "a sociedade atual é conhecida como Sociedade da Informação ou do Conhecimento, na qual se tem o acesso democratizado, universal, global e total à informação através dos meios de comunicação e equipamentos eletrônicos com acesso à internet". Porém, para gerar conhecimento, as pessoas precisam interagir em rede e colaborar umas com as outras de forma que as diversas informações se inter-relacionem mutuamente, criando uma rede de significados que se interiorizam. Nessa sociedade da informação, as TIC foram disseminadas no nosso dia a dia, no trabalho, na escola, na faculdade, em todos os lugares. Assim, a forma de ensinar e aprender mudou, pois a informação está disponível a qualquer hora e em qualquer lugar. 
O fato de todas as áreas da sociedade terem passado a utilizar as TIC faz com que as Instituições de Ensino Superior (IES) acompanhem essa mudança, visto que, no desenvolvimento das diversas profissões e na busca pelo conhecimento, as tecnologias são consideradas elementares e essenciais (COSTA, 2005). Portanto, não adianta apenas ter acesso a elas, e não saber usá-las de forma dinâmica, por isso o professor tem um papel fundamental nesse processo, fazendo com que o aluno seja questionador, pesquisador e construa seu conhecimento. Moran (2012, p. 33) afirma:

[...] a aquisição da informação dependerá cada vez menos do professor. As tecnologias podem trazer hoje dados, imagens, resumos de forma rápida e atraente. $O$ papel do professor - papel principal - é ajudar o aluno a interpretar esses dados, a relacioná-los e a contextualizá-los. O papel do educador é mobilizar o desejo de aprender, para que o aluno se sinta sempre com vontade de conhecer mais (grifo nosso).

A afirmação acima tem relação com a teoria de Siemens segundo a qual o professor apoia as interações dos alunos para que possam fazer conexões com as existentes e os ajuda nos novos caminhos, utilizando novos recursos de aprendizagem.

Ensinar e aprender, hoje, não se limita ao trabalho dentro da sala de aula. Implica modificar o que se faz dentro e fora dela, nos ambientes presencial e virtual, organizando ações de pesquisa e de comunicação que possibilitem continuar aprendendo em ambientes virtuais. Muitas ações podem ser feitas como: pesquisar textos e artigos na internet, trocar mensagens, discutir questões em fóruns ou em salas de aula virtuais, divulgar pesquisas e projetos. Um dos grandes desafios para o educador de hoje é ajudar a tornar a informação significativa, a escolher as informações verdadeiramente importantes entre tantas possibilidades, a compreendê-las de forma cada vez mais abrangente e profunda e a torná-las parte do nosso referencial.

A incorporação das TIC dentro do ensino e aprendizagem é um fenômeno relevante que influenciou a evolução recente da educação superior. Segundo a Organização para a Cooperação e Desenvolvimento Econômico (OECD, 2015, p. 43), “o e-learning está a tornarse cada vez mais relevante no domínio do ensino superior”. Pode-se dizer que o e-learning foi baseado na educação a distância $(\mathrm{EaD})$ que foi a primeira forma de educação além dos muros da sala de aula. A educação a distância foi iniciada no século XIX com o ensino por correspondência cujo material era enviado para o aluno. A geração que utilizou ferramentas tecnológicas foi a do rádio e da TV. A segunda geração incorporou as fitas cassetes e os vídeos 
para a transmissão do material. A terceira geração se solidificou com o uso dos computadores e, finalmente, com o advento da internet, criaram-se novas possibilidades de ensino e aprendizagem. Segundo OECD (2015, p. 41), "um dos mais importantes desenvolvimentos na educação superior mais recente foi o chamado "open education movement" que, impulsionado pela incorporação de TIC no ensino superior, levou ao surgimento de recursos educacionais abertos ${ }^{3}($ REA)".

Os Ambientes Virtuais de Ensino e Aprendizagem (AVEA) têm promovido mudanças significativas na forma de ensinar e aprender, afetando a relação aluno-professor, sejam eles utilizados na modalidade presencial ou a distância. Segundo Hew e Cheung (2014), o ambiente virtual de aprendizagem tem o objetivo de facilitar a interação aluno-professor, fazendo uso de ferramentas capazes de enriquecer esse processo, como chats, fóruns e tarefas. A utilização dessas "interfaces", com o intuito de aumentar a eficácia e eficiência da aprendizagem por parte dos professores e utilizadores das mesmas, tornou-se uma realidade no século XXI. Uma das prioridades dos AVEA é a troca de informações entre os participantes, de modo que isso melhore a interação entre eles.

A forma de aprendizagem que embasa as necessidades do nosso tempo se fundamenta em um modelo dinâmico, no qual o aluno é levado em conta com todo o seu arsenal de conhecimento. A verdadeira aprendizagem se dá quando o aluno (re)constrói o conhecimento e forma conceitos sólidos sobre o mundo, o que vai lhe proporcionar meio de agir e reagir diante da realidade. Esse aluno precisa ser autônomo, no sentido de gerir sua aprendizagem, ser capaz de organizar sozinho o seu estudo, sem total dependência do professor, administrando eficazmente o seu tempo de dedicação ao aprendizado e escolhendo de forma eficiente as fontes de informação disponíveis. Quando se fala em Ensino e-learning ou EaD, pretende-se que o aluno aplique o conceito de autonomia na educação. Para Moore e Kearsley (2008, p. 301), “o conceito de autonomia do aluno significa que os alunos têm capacidades diferentes para tomar decisões a respeito do seu próprio aprendizado".

Hoje, na sociedade do conhecimento, faz-se necessário, então, construir e talvez reconstruir os novos rumos dessa educação cidadã, dinâmica, libertadora, autônoma, consciente e popular, respaldando o aprendizado para a vida, procurando orientar o aluno para uma via de produção coletiva, mas, ao mesmo tempo, desenvolvendo a autonomia em cada um. 
Em seus estudos, Wissmann (2006), apud Serafini (2012, p.73), afirma que “... a autonomia do aprendiz requer não só a aprendizagem, mas aprender a aprender". Segundo o autor, a concepção de autonomia pode ser entendida como produto de um processo interativo definido pela essência interdependente de cada indivíduo como ser social que é. Assim, os aprendizes em EaD também podem ser ajudados a adquirir autonomia por meio de um processo de interação semelhante à aprendizagem prensencial. Com isso, a figura do professor/mediador é de extrema importância nesse processo.

Segundo Guimarães (2012, p. 128):

A aprendizagem em tempos de convergência digital é um processo fundamentalmente colaborativo, em que as redes sociais se destacam ao redor de interesses comuns, facilitando e orientando a construção do conhecimento; $\mathrm{O}$ aprendente assume um papel central no processo de aprendizagem e não pode ser tratado como um receptor passivo da informação, devendo necessariamente ser incluído como um autor, cocriador, avaliador e comentador crítico [...].

Percebe-se na educação que a questão da autonomia envolve outros fatores e não somente a vontade do aluno. Algumas variáveis influenciam no processo para se atingir a autonomia nos diversos ambientes de aprendizagem, são elas: a vontade e organização do aluno, o currículo nacional (presencial e a distância, os quais não têm flexibilidade), a estrutura física da faculdade, as TIC disponíveis, a metodologia, a forma de avaliação. Na modalidade a distância, o aluno tem a liberdade de aprender por meio da mediação pela tecnologia, interagindo através das diversas ferramentas com colegas e professores. O papel do professor deve ser de mediador nessa aprendizagem, como também o aluno deve ter habilidade técnica, saber tomar decisões em relação ao que quer aprender, desenvolver seu plano pessoal de aprendizagem e saber buscar recursos para sua aprendizagem.

Nos dias de hoje, fala-se muito das metodologias ativas, sendo uma das mais conhecidas a Sala de Aula Invertida, cujo próprio nome já diz: é o contrário do que acontece na educação tradicional. Para Bergmann e Sams (2016, p.11), "basicamente o conceito de sala de aula invertida é o seguinte: o que é tradicionalmente feito em sala de aula, agora é executado em casa, e o que é tradicionalmente feito como trabalho de casa, agora é realizado em sala de aula". O aluno estuda em casa (vê os vídeos, pesquisa, faz leituras de textos), e o espaço da sala de aula é para tirar dúvidas, dialogar com os professores e colegas, fazer atividades e resolver problemas. Dessa forma, a aprendizagem é centrada nos alunos, eles são mais ativos, 
aproveitam melhor o tempo no presencial, e têm mais autonomia no seu processo de aprendizagem.

Outra metodologia ativa, a Aprendizagem baseada em problemas (ABP) ou ProblemBased Learning (PBL), originou-se nas Faculdades de Medicina da Universidade de Mcmaster, entre as décadas de 60 e 70. Ela tem como princípio o uso de problemas da vida real para estimular o desenvolvimento de pensamento crítico e habilidades de solução de problemas e a aprendizagem de conceitos fundamentais da área de conhecimento estudada. Ribeiro (2005, p. 32), "embora concebida para o ensino da Medicina, seus princípios têm se mostrado suficientemente robustos para fundamentar implementações no ensino de outras áreas de conhecimento (BOUD; FELETTI, 1999) e em outros níveis educacionais, isto é, nos ensinos fundamental (e.g., GLASGOW, 1997) e médio (e.g., FOGARTY, 1998) ”.

\section{PERCURSO METODOLÓGICO}

Este estudo está fundamentado em pesquisa qualitativa com abordagem descritiva, no qual se buscou analisar o olhar do professor sobre a questão da autonomia do aluno nos ambientes de aprendizagem. Ele foi dividido em duas etapas, a revisão da literatura e depois a aplicação do questionário com os professores. Na revisão da literatura, foram analisados 129 artigos, dos quais 15 fazem parte da investigação, as bases de dados utilizadas foram CAPES, Scielo, Google Scholar, e Biblioteca Brasileira de Dissertações e Teses. Para os artigos selecionados teve-se como critério de inclusão todos que trouxessem o contexto da percepção ou olhar do professor frente à autonomia do aluno. Os descritores usados nas pesquisas foram: "PROFESSOR UNIVERSITÁRIO" AND AUTONOMIA DO ALUNO; "OLHAR DO PROFESSOR” AND “AUTONOMIA DO ALUNO”; "PERCEPÇÃO DO PROFESSOR”AND “AUTONOMIA DO ALUNO”; "PERCEPÇÃO DO PROFESSOR” AND “AUTONOMIA DISCENTE"; "TEACHER LOOK” AND "STUDENT AUTONOMY"; "TEACHER PECEPCION" AND "STUDENT AUTONOMY”. Os descritores foram combinados variando entre o título e qualquer parte do texto, usando o conector de junção AND. A maioria dos resultados trazem a questão da percepção do professor em diversas áreas, situações específicas, mas não relacionada à autonomia. E os artigos que tratavam sobre a autonomia eram sobre a mesma na EaD, ou a importância da autonomia em um curso. 
A pesquisa aconteceu em duas instituições públicas federais na cidade de Maceió, Alagoas. O público alvo foram professores do ensino superior, no qual foi traçado o perfil deles quanto ao gênero (13 mulheres e 18 homens); quanto à idade (entre 27 e 50 anos); quanto à titulação (4 especialistas, 12 mestres e 15 doutores). Como instrumento de coleta de dados, utilizou-se um questionário distribuído para 50 professores, 20 presenciais e 30 por e-mail, tendo sido obtido um retorno de 31 . O questionário foi composto de quinze (15) perguntas, que se encontram no apêndice A, divididas em duas partes: caracterização dos sujeitos envolvidos na pesquisa e processo de aprendizagem. Nele, havia perguntas de ordem escalar e abertas; as primeiras foram analisadas quantitativamente usando o Excel, enquanto as abertas passaram por uma análise, utilizando-se uma abordagem dedutiva nomotética ${ }^{4}$ que, segundo Gibbs (2009, p. 20) [...], "tenta mostrar o que as pessoas, eventos e contextos têm em comum e explicá-los em termos dessas características comuns".

\section{ANÁLISE DOS DADOS}

No questionário dividido em duas partes foram abordadas as variáveis (TIC, metodologia, interação com os pares, infraestrutura) que influenciam no processo de aprendizagem.

\section{1 $1^{\text {a }}$ parte: Caracterização dos sujeitos envolvidos na pesquisa}

Na primeira parte da coleta de dados, buscou-se verificar se o professor consegue visualizar essa autonomia nas atitudes do dia a dia dos alunos, como: organização dos estudos, cumprimento dos prazos das atividades, proatividade, interação com os colegas e outras características que poderão levá-lo a essa autonomia.

No questionário, as duas primeiras perguntas queriam saber o que os professores achavam sobre autonomia, e em seguida foram formuladas seis (6) perguntas de escala linear ${ }^{5}$ (5 - Totalmente de acordo; 4 - Parcialmente de acordo; 3 - Indiferente; 2 - Parcialmente em desacordo e 1 - Totalmente em desacordo), e três (3) perguntas abertas.

Em relação à primeira pergunta (o que é autonomia?), os professores tinham visões semelhantes do conceito: [P1] "É a liberdade de escolher e agir. " [P2] "É a capacidade de se 
autogerir. " [P3] "Refere-se à habilidade de tornar-se agente de seu próprio destino, de tornarse um ser ativo ao invés de passivo em tudo que almeja. " [P4] "Conseguir executar ações, atividades sem auxílio de outrem. ”

$\mathrm{Na}$ segunda pergunta (para você, o que é um aluno autônomo?), alguns deles responderam: [P5] “Aquele que desenvolve os exercícios, tarefas e projetos sem a necessidade de tirar dúvidas constantemente junto ao professor. " [P6] "Aquele que é capaz de aprender sozinho, ensinar e estimular novas atitudes nos professores." [P7] "Um aluno com a devida autonomia possui a habilidade de gerenciar seu aprendizado, planejando, buscando, filtrando e transformando informação em conhecimento, ao mesmo tempo colocando aquele conhecimento em prática e interagindo com outros, que finalmente resultarão no desenvolvimento das habilidades demandadas para seu campo de atuação profissional ou seu interesse. " [P8] "É o aluno raro, pois a maioria dos alunos precisa ser conduzido para o aprendizado. A autonomia é alcançada pelo aluno quando ele vai além do que aprende na sala de aula."

Quanto a essa questão, percebe-se que o aluno deve planejar, executar e gerenciar seu aprendizado, tendo autonomia nas suas escolhas, que ele deve ir além da sala de aula. Para Moore e Kearsley (2008), a autonomia é um processo de maturação, enquanto Freire (1996) e Knowles (1990) acreditam que se deve levar em consideração a experiência do aluno. Acreditase que exista algumas vezes uma autonomia individual, mas muitos alunos estão acostumados desde o ensino fundamental a somente esperar pelo professor, portanto, concorda-se com Moore e Kearsley (2008) quando dizem que a autonomia é um processo de amadurecimento no processo de aprendizagem. Corrobora-se o pensamento de Knowles (1975, p.14) que diz: "É trágico que a maioria de nós só saiba ser ensinado, nós não aprendemos a aprender”.

Em sequência, as seis perguntas foram divididas em dois blocos. No gráfico 1 estão as perguntas de ordem escalar do primeiro bloco, que se refere a autonomia individual do aluno. 


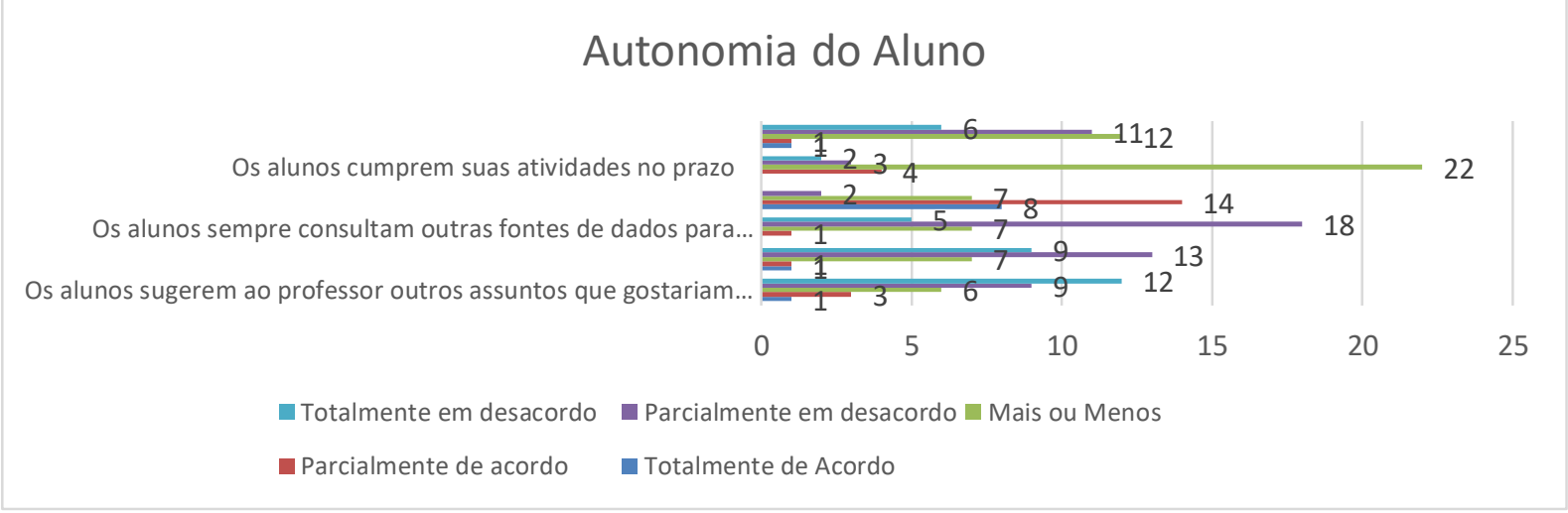

\section{Gráfico 1}

Fonte: próprios autores

Na primeira, ao serem questionados se os alunos sempre organizam o tempo de estudos, dezessete professores $(54,8 \%)$ afirmaram que percebem muito pouco essa organização em seus alunos; apenas dois professores $(6,5 \%)$ consideram que seus alunos organizam o seu tempo para a realização das atividades. Outra questão: os alunos cumprem suas atividades no prazo? A maioria dos professores respondentes $(71 \%)$ confirmaram que relativamente. Essa questão encontra-se vinculada ao item anterior; considerando que, como os alunos não organizam seu tempo, consequentemente não podem dar conta das atividades dentro de prazos. Na sequência, houve o questionamento se os alunos se limitam a estudar apenas o que é disponibilizado pelo professor. Nessa questão, a maioria dos professores (71\%) concordam que sim. É difícil para o professor medir a questão de como os alunos ampliam seus conhecimentos, pois é uma questão individual, e isso depende da postura de cada aluno. Pela vivência na docência, percebe-se que pouquíssimos alunos pesquisam e estudam além do que o professor disponibiliza.

Uma análise de variância estatística desses dados (estabelecida por Robert Aylmer Fisher (1890 - 1962) mostrou que, em um nível de significância de 5\%, os dados são significativamente diferentes, mas não as variâncias - principalmente devido à margem de respostas escolhidas da escala Likert. O gráfico 2, do tipo box plot (ou diagrama de caixa e bigodes), resume o número das frequências absolutas de cada um dos respondentes numa escala. Os valores extremos também se encontram destacados para cada resposta da escala 1 a 5 de Likert. Por exemplo, 22 docentes (de um total de 31) afirmaram estar indiferentes sobre se os alunos cumprem suas atividades no prazo. Pode-se citar que houve grande variabilidade na resposta "parcialmente em desacordo". Outra caraterística relevante é que houve respostas 
simétricas em torno dos respectivos valores centrais apenas nos extremos da escala: "totalmente de acordo" e "totalmente em desacordo".

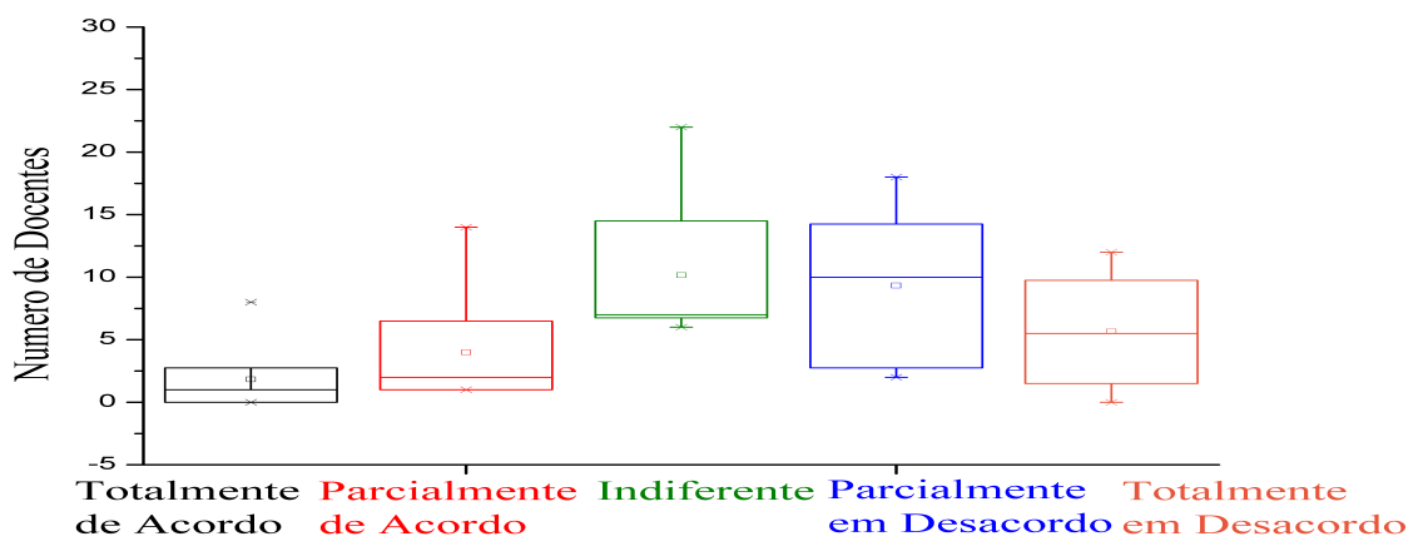

Gráfico 2

Fonte: próprios autores

Na segunda parte das perguntas, a quarta questão indagou se os alunos consultam outras fontes de dados para ampliar seu conhecimento. A maioria dos professores (80\%) não acreditam que os alunos sempre consultem outras fontes, havendo apenas $3,2 \%$ que acreditam nisso. $\mathrm{Na}$ maioria das vezes, os alunos acessam apenas o Youtube para encontrar vídeos que os ajudem na explicação de um determinado assunto. Na pergunta seguinte, buscava-se saber se os alunos sugerem textos, livros, vídeos para os colegas. A maioria dos professores percebem que os alunos raramente fazem esse tipo de indicação. A autora 1, afirma: "No ensino presencial e a distância, eu sempre utilizo os AVEA e nos cursos e disciplinas é criado um Fórum Café, no qual os alunos podem trocar informações, colocar vídeos, textos, sugerir livros, congressos, e raramente eles postam alguma coisa. ". Na penúltima pergunta, procurou-se verificar se os alunos sugeriam ao professor outros temas em relação ao assunto estudado. A maioria estava "pouco de acordo/totalmente em desacordo" (67,7\%) e os demais professores $(32,3 \%)$ dividiram-se nas outras respostas.

Nas perguntas abertas foi feita uma análise das respostas que os professores deram, tendo sido gerado um percentual comum às mesmas. Na primeira questão aberta que questiona se o aluno tem autonomia no processo de aprendizagem, o gráfico 3 resume as respostas. 


\section{$\mathrm{O}$ aluno tem autonomia no processo de aprendizagem?}

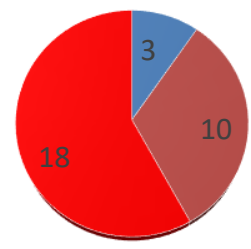

- Sim - Pouca - Não

\section{Gráfico 3}

Fonte: próprios autores

Os professores fizeram comentários importantes sobre essas questões. [P1] "Na área que atuo - Dança - a autonomia é essencial [...] mas, em geral, os alunos vão gradualmente entendendo seus corpos, suas danças e que inevitavelmente seus processos de aprendizagem devem ser autônomos. " [P2] "Não acredito, pois, a maioria vai às aulas esperando apenas a transmissão do conhecimento de forma passiva." [P3] "Acredito que muito pouco, visto que ainda utilizo muito do modelo tradicional de ensino: professor ministra conteúdo. Mas, no último bimestre ou avaliação, os alunos possuem mais autonomia, visto que passo um projeto para ser desenvolvido, então eles que precisam verificar como irão fazer, do que precisam. " [P4] "Não. Em geral [...] se contentam em estudar o que sabem que será cobrado. " [P5] "Não. São totalmente dependentes e procuram fazer o mínimo do que é proposto."

$\mathrm{Na}$ segunda questão que pergunta se o professor está aberto para que seus alunos sugiram novas possibilidades de avaliação, 30 responderam que sim, e apenas 1 disse pouco aberto. Eles ressaltaram a importância de as sugestões dos alunos serem construtivas e com respeito, porém alguns não abrem mão de ter pelo menos uma avaliação no formato de prova. Algumas falas dos professores. [P6] "Sim. Porém não abro mão de ter pelo menos $60 \%$ da disciplina avaliados por meio de prova escrita. Acredito que sem essa cobrança não estudariam seriamente o que foi dado. "[P7] "Sim e como trabalho com aprendizagem por projetos, minhas avaliações são totalmente baseadas no processo (desenvolvimento / maturação das habilidades dos alunos) e no produto (resultado) que foi gerado pelo projeto. Assim, a avaliação não é só feita por mim, mas por membros de sua equipe, e por si mesmo, pois os melhores avaliadores somos nós mesmos. Cada um sabe se ocorreu aprendizagem em seu íntimo ou se foi um mero passo de aprendizagem mecânica para obter uma nota, que é o que geralmente ocorre em sala 
de aula." [P8] "Pouco. O professor acaba criando seu método de trabalho ao longo dos anos e, de certa forma, se acomoda. " [P9] "Sim. Tento conciliar aprendizagem tradicional e utilizar conceitos de PBL (Aprendizagem baseada em problemas). As avaliações de aprendizagem normalmente são projetos baseados em PBL, no qual tento avaliar a capacidade de o aluno chegar a um resultado para um problema."

Percebe-se que 58\% dos professores não acreditam que os alunos tenham autonomia no processo de aprendizagem, enquanto 32,3\% acreditam que eles tenham pouca autonomia, podendo adquiri-la mais com o uso das TICs e com a mudança na postura do professor; notouse, por fim, que apenas 9,7\% dos professores acreditam que os alunos têm autonomia. Quanto a essa questão, considerando o modelo educacional que temos nas universidades, os alunos têm pouca autonomia. A legislação que rege o modelo educacional brasileiro dificulta a liberdade do aluno na escolha do que estudar, como estudar e onde estudar. Para Siemens (2005, p. 5), "um dos princípios do Conectivismo é escolher o que aprender, e o significado da informação recebida é visto através das lentes de uma realidade em mudança”.

A terceira questão aberta traz: como deve ser o perfil do professor para que possa proporcionar uma maior autonomia ao aluno no processo de aprendizagem? O perfil traçado pela maioria dos entrevistados foi que esse professor deve ter o perfil de orientador, facilitador do aprendizado, motivador, ser aberto às TICs, atualizado para trabalhar com novas metodologias de ensino, sensível, ter humildade e deve estimular a pesquisa e a leitura.

A próxima etapa tratará das questões relacionadas ao processo de aprendizagem dos alunos.

\subsection{2 ${ }^{\mathrm{a}}$ Parte: Processo de aprendizagem}

Conforme os pensamentos de teóricos como Vygostky e Piaget, para que aconteça aprendizagem, é preciso haver a inter-relação entre as condições internas (dos sujeitos) e as condições externas (do meio) para a autoconstrução psicossocial das pessoas através de sua aprendizagem em particular. Assim, o processo de aprendizagem é complexo pois envolve diversas variáveis, não somente aluno e professor.

São muitos os fatores relacionados com o processo de aprendizagem, destacando-se a motivação, a percepção de autoeficácia e a autorregulação, que por sua vez contribuem para o 
investimento, agência e estratégias que cada indivíduo utiliza para concretizar um objetivo ou tarefa. Assim, o processo de ensino-aprendizagem é um processo de formação humana em que ocorre uma produção autônoma do conhecimento, de forma que o ser humano possa saber elaborar críticas sobre aquilo que está aprendendo.

A segunda parte do questionário analisada foi o processo de aprendizagem. Eles responderam 6 perguntas abertas que estão relacionadas com variáveis que interferem diretamente na aprendizagem, são elas: interação com os pares, metodologias e TIC.

O primeiro questionamento: Você acredita que a interação com os colegas na sala de aula influencia no processo de aprendizagem dos alunos? Por quê? Vinte e nove professores $(93,6 \%)$ responderam que acreditam que influencia sim, e dois $(6,4 \%)$ não responderam. Baseado nos teóricos que embasaram a pesquisa, acredita-se que a interação entre os alunos pode gerar perturbações as quais irão gerar conhecimento. Os alunos falam a mesma linguagem, usam as mesmas tecnologias, facilitando, assim, o entendimento entre eles.

Essa questão faz lembrar Vygotsky quando ele afirma que, quando você interage e tem ajuda dos pares em uma atividade, você tem a "boa aprendizagem" porque ocorre na ZDP. A afirmação dele se comprova nas falas dos professores. [P10] "Claro! Os alunos precisam auxiliar os colegas na resolução e no esclarecimento de problemas; compartilhar novos conhecimentos e descobertas com a equipe; facilitar o acesso às informações para auxiliar o trabalho do grupo; ouvir e respeitar a opinião dos colegas, ao mesmo tempo em que sentem à vontade para expor seus pontos de vista e se comprometer com as decisões e objetivos definidos pelo grupo. Sim, influencia muito. Em ocasiões, a linguagem e as expressões que os alunos utilizam para se comunicar entre si funcionam melhor do que a linguagem do professor. "[P11] "Sim, porque os colegas possuem uma linguagem que o professor não tem para interagir entre si. Eu provoco os alunos sempre." [P12]. "Sim, a troca de saberes é essencial para a construção do mesmo, bem como para a socialização entre eles."

O segundo questionamento, representado no gráfico 4, mostra que $77,4 \%$ dos professores incentivam seus alunos a interagirem dentro e fora da sala de aula, $12,9 \%$ são indiferentes e $9,7 \%$ não responderam. 


\section{Você provoca, dialoga com os alunos para incentivar a} interação dentro e fora da sala?

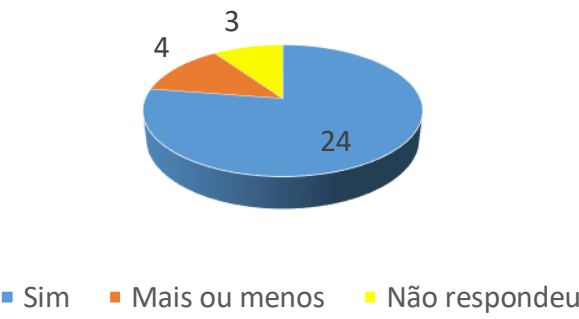

Gráfico 4 - pergunta aberta

Fonte: próprios autores.

O terceiro questionamento traz: Que fatores você acredita que influenciam no processo de aprendizagem do aluno de forma positiva ou negativa? A maioria $(64,5 \%)$ acredita que influenciam de forma positiva. Os fatores positivos listados foram: disciplina, responsabilidade, didática do professor, interação com os colegas, uso de TIC, projetos reais e o hábito de ler. Quanto aos fatores negativos, foram mencionados: falta de interesse, cansaço, muitas distrações tecnológicas, salas cheias, professor desestimulado, estrutura ruim (salas, laboratórios), currículo rígido e métodos tradicionais de ensino.

Acredita-se que todos os fatores positivos e negativos são pertinentes e muitas vezes comuns na maioria da escolas e faculdades, portanto a vontade do aluno de aprender, de inovar, de trabalhar em grupo faz o diferencial nesse processo de desenvolvimento da autonomia.

O quarto questionamento: De que forma as TIC influenciam nesse processo? As respostas estão representadas no gráfico 5.

De que forma as TIC influenciam nesse processo?

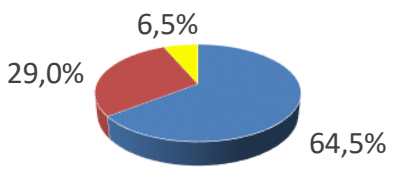

- Positiva - Positiva e negativa (depende como são utilizadas) - Não respoderam

Gráfico 5 - pergunta aberta

Fonte: próprios autores.

Siemens (2005, p.4) "afirma que a inclusão da tecnologia e do fazer conexões como atividades de aprendizagem começa a mover as teorias da aprendizagem para uma idade 
digital". Não podemos mais, pessoalmente, experimentar e adquirir a aprendizagem de que necessitamos para agir.

Para Moran (2015, p. 16),

o que a tecnologia traz hoje é a integração de todos os espaços e tempos. O ensinar e o aprender acontecem numa interligação simbiótica, profunda, constante entre o que chamamos mundo físico e mundo digital. Não são dois mundos ou espaços, mas um espaço estendido, uma sala de aula ampliada, que se mescla, hibridiza constantemente. Por isso a educação formal é cada vez mais blended, misturada, híbrida, porque não acontece só no espaço físico da sala de aula, mas nos múltiplos espaços do cotidiano, que incluem os digitais.

O quinto questionamento: Você acredita que a metodologia utilizada pelo professor influencia na autonomia do aluno? Por quê? A maioria dos professores (87\%) responderam afirmativamente, pois pode estimular o aprendizado do aluno, e ele pode ser corresponsável pelo seu aprendizado; dois $(6,5 \%)$ disseram que isso acontece, em parte, pois acredita-se que a autonomia depende muito mais do aluno do que do professor e dois $(6,5 \%)$ não responderam. Segundo Moran (2015, p. 4), "quanto mais aprendamos próximos da vida, melhor. As metodologias ativas são pontos de partida para chegar a processos mais avançados de reflexão, de integração cognitiva, de generalização, de reelaboração de novas práticas".

O sexto questionamento: Hoje se fala muito em metodologias ativas. Você realmente acredita que elas possam influenciar na autonomia do aluno? Como? Vinte professores $(64,5 \%)$ responderam sim, quatro $(12,9 \%)$ disseram que relativamente, dois $(6,5 \%)$ disseram que não, e cinco $(16,1 \%)$ disseram que ainda não estavam aptos a responder, pois ainda estão em fase de aprendizado dessas metodologias. Seguem os comentários dos professores: [P13] “[...] inclusive tenho feito uso de algumas de suas práticas. Elas permitem dar voz ao aluno, visam acompanhar o seu desenvolvimento como um ser único, de modo que a condução da disciplina seja relacionada ao ritmo de assimilação de cada aluno. Estimulam sua criatividade, pesquisa e independência ao promover atividades que despertam a curiosidade e a necessidade de tomadas de decisões individuais e coletivas. "[P14] “Acredito que sim, porque existem diversas metodologias por meio das quais o professor consegue semear a semente da curiosidade no aluno. Uma vez que o aluno se sente desafiado, ele procura estudar, pesquisar e sanar suas dúvidas e curiosidades. "[P15] "A metodologia ativa coloca o aluno como principal agente do seu aprendizado. $\mathrm{O}$ professor cria fatores estimulantes para esse aprendizado, mas é o aluno o 
centro das atenções. A palavra indivíduo vem de individual, portanto cada pessoa é responsável pelo seu processo de evolução. O professor nesse contexto de sala de aula, propõe as ferramentas necessárias para o processo de evolução, crescimento e amadurecimento, mas cada um projeta o seu caminho e tem suas ações e atitudes próprias, podendo ou não desenvolver a habilidade de autonomia."

Para Moran (ibid., p.17), "as metodologias precisam acompanhar os objetivos pretendidos. Se queremos que os alunos sejam proativos, precisamos adotar metodologias em que os alunos se envolvam em atividades cada vez mais complexas, em que tenham que tomar decisões e avaliar os resultados, com apoio de materiais relevantes. Se queremos que sejam criativos, eles precisam experimentar inúmeras novas possibilidades de mostrar sua iniciativa”.

Pode-se, portanto, a partir dos resultados, concordar com as ideias de Moran (2015), segundo o qual as escolas e faculdades devem introduzir no seu cotidiano as metodologias ativas, usando modelos centrados no aluno, e eles possam aprender através de problemas reais, de jogos, de atividades individuais/grupo e através de projetos integradores.

\section{CONSIDERAÇÕES FINAIS}

Os autores acreditam que a educação, para promover a autonomia, tem que formar o indivíduo na sua totalidade, isto é, não somente na capacitação técnico-científica, mas também na ética, política e social. A autonomia tem que ser dialógica a fim de preparar o sujeito para o exercício da democracia

O ideal seria que as teorias de Piaget, Vygotsky, Siemens fossem colocadas em prática nas escolas e nas faculdades, de forma que esses espaços fossem formadores dessa autonomia. Acredita-se que o sistema de educação brasileiro promove a educação bancária, tão condenada por Freire. Precisa-se que comecem a mudar as estruturas de sala de aula tradicional para salas multifuncionais, que o currículo seja mais flexível, que os professores utilizem metodologias ativas as quais ajudam a desenvolver habilidades necessárias para o aluno do século XXI. Todas essas mudanças estruturais e comportamentais precisam ser postas em prática progressivamente, não é fácil mudar uma estrutura que permanece quase imutável há séculos.

Os professores da pesquisa disseram que a maioria dos alunos (58\%) não tem autonomia no seu processo de aprendizagem, $32 \%$ que têm pouca e somente 9,6\% têm autonomia. Percebe- 
se na primeira sequência de perguntas relativas à autonomia do aluno que 93,5\% não organizam seu tempo de estudo; $87 \%$ não cumprem as atividades no prazo e 96,8\% limitam-se ao que o professor passa, não indo à busca de outras fontes de dados. Eles também acreditam que um fator importante para se buscar essa autonomia discente é a interação com os colegas, $(93,55 \%$ disseram que eles têm uma mesma linguagem e isso facilita na hora de resolver problemas e tirar dúvidas). Outro fator importante nesse processo é a inserção das tecnologias no dia a dia dos discentes $(64,5 \%$ acreditam que elas são grandes aliadas nesse processo, enquanto $29 \%$ dizem que depende de como são utilizadas). E um fator de grande relevância foi que $87 \%$ dos professores acreditam que as metodologias utilizadas por eles podem influenciar na busca dessa autonomia do aluno. Em geral, eles afirmaram que os alunos estão acostumados ao modelo passivo no qual vêm enraizados desde o ensino básico, que no geral só estudam o material disponibilizado pelo professor e que é preciso não só fazer reflexões sobre as propostas pedagógicas ou sobre a prática do professor, mas também problematizar a própria sociedade em que vive esse professor.

De acordo com Barbosa e Moura (2013, p. 55), para que ocorra a aprendizagem ativa, os professores devem, na sua prática de ensino, "favorecer ao aluno atividades de ouvir, ver, perguntar, discutir, fazer e ensinar". O aluno deve ser estimulado a construir o conhecimento ao invés de recebê-lo de forma passiva do seu professor. O professor passa a atuar como orientador e facilitador do processo de aprendizagem. Corrobora-se a linha de pensamento de Shor $(1992,1996)$ apud Silva (2014, p. 105), "propõe o conceito de empowerment, que diz respeito a uma pedagogia centrada no aluno e numa aprendizagem cooperativa".

É possível concordar com Delors quando afirma que a prática pedagógica deve preocupar-se em desenvolver aprendizagens fundamentais, ao longo da vida do aluno, baseada nos pilares: "Aprender a conhecer", no qual a aluno deve ter prazer no ato de compreender, descobrir, construir e reconstruir; "Aprender a fazer", o aluno precisa saber enfrentar situações no dia a dia, resolver conflitos, comunicar-se; 'Aprender a conviver", ele precisa aprender a conviver com os outros, a trabalhar em equipe; “Aprender a ser”, ele deve desenvolver sentido ético, sensibilidade, autonomia, criatividade, iniciativa.

Considerando os relatos dos professores, eles acreditam que a inserção de TIC e a inserção de metodologias como PBL, a sala de aula invertida, possam desenvolver essa autonomia, mas isso tem que ser iniciado desde os ensinos fundamental e médio. Eles acreditam 
que essas metodologias podem trazer uma maior dinamicidade, como também uma mudança de postura do aluno para que ele se torne mais ativo e participativo. Alguns comentários que ratificam essa conclusão: [P19] "Elas podem dar uma oportunidade para que o aluno a desenvolva. Sempre vai depender dele [...]. Ao se deparar com um problema, um cenário, um projeto e este for ligado à REALIDADE do aluno - ou seja, ele precisa ser AUTÊNTICO!!." [P20] "A manutenção da consciência da necessidade de adquirir conhecimento para solucionar um problema, como no exemplo do PBL, é o agente motivador da aquisição de conhecimento do aluno. E não a vontade do professor apenas. " [P21] "Sempre acreditei que a metodologia pautada num contexto onde haja um currículo que atente para as necessidades dos sujeitos o torna mais independentes."

Percebe-se que os alunos ainda não têm uma autonomia real no seu processo de aprendizagem, pois existe a interferência de vários fatores externos (as políticas públicas, o currículo, as estruturas de sala de aula, a formação docente, as metodologias) e internos (motivação, vontade de aprender, disciplina para estudar) que dificultam o desenvolvimento da autonomia. Conclui-se que na aprendizagem pode-se ter níveis de autonomia do aluno, concatenando e modificando os fatores que tanto influenciam nesse processo. Como trabalho futuro, os pesquisadores pensam em propor uma matriz com níveis de autonomia, como também orientações para os envolvidos colaborarem no desenvolvimento de um aluno mais autônomo.

\section{REFERÊNCIAS}

ALMEIDA, Maria Elizabeth B. de; SILVA, Maria das Gracas M. da. Currículo, Tecnologia e Cultura Digital: espaços e tempos de Web Currículo. Revista e-Curriculum. São Paulo, v. 7, n. 1, p. 1-19, Abril 2011. Disponível em:

https://revistas.pucsp.br/index.php/curriculum/article/viewFile/5676/4002. Acesso em: 03 abr. 2018.

BARBOSA, Eduardo Fernandes; MOURA, Dácio Guimarães. Metodologias ativas de aprendizagem na Educação Profissional e Tecnológica. Boletim Técnico do Senac. Senac, Rio de Janeiro, v. 39, n. 2, p.48-67, maio/ago. 2013. Disponível em: http://www.bts.senac.br/index.php/bts/article/view/349/333 . Acesso em: 01 jun. 2018.

BOULD, D.; FELETTI, G. The challenge of problem-based learning. Londres: Kogan Page, 1999. 
BELLAN, Zezina. Andragogia em ação: como ensinar sem se tornar maçante. São Paulo: Z3, 2005.

BERGMANN, Jonathan; SAMS, Aaron. Sala de aula invertida: uma metodologia ativa de aprendizagem. Tradução: Afonso Celso da Cunha Serra. Rio de Janeiro: LTC, 2016.

BOTELHO, Antonio; FIALHO, Isabel. Aprendizagem no ensino superior: relações com a prática docente. 2009. Disponível em:

https://dspace.uevora.pt/rdpc/bitstream/10174/7015/1/Aprendizagem\%20no\%20ensino\%20su perior\%20Rela\%C3\%A7\%C3\%B5es\%20com\%20a\%20pr\%C3\%A1tica\%20docente\%2C\%20 pp.\%20984-996.pdf . Acesso em: 24 ago. 2017.

CAETANO, Luciana Maria. A epistemologia genética de Jean Piaget. 2010. Disponível em: http://www.ip.usp.br/portal/index.php?option=com_content\&id=1797:a-epistemologiagenetica-de-jean-piaget\&Itemid=97 . Acesso em: 28 out. 2017.

COELHO, Marcos Antonio P.; DUTRA, Lenise R.; MARIELI, Joani. Andragogia e Heutagogia: práticas emergentes na educação. Revista Transformar. n. 8. p. 97-107, 2016. Disponível em:

http://www.fsj.edu.br/transformar/index.php/transformar/article/viewFile/87/83 . Acesso em: 15 mar. 2018.

COSTA, C. Educação, imagem e mídias. São Paulo: Cortez, 2005.

DELORS, Jacques. Educação: um tesouro a descobrir. São Paulo: Cortez. Brasília, DF: MEC: UNESCO, 2003.

ESCUDERO, Juan M.; TRILLO, Felipe. O desenvolvimento profissional dos professores. Crise do currículo, das práticas, dos efeitos da formação docente? In: FLORES, Maria Assunção.; MOREIRA, Maria Alfredo.; OLIVEIRA, Lia Raquel (Orgs.). Desafios Curriculares e Pedagógicos na Formação dos Professores. 2. ed. Portugal: Edições Pedagogo e De facto Editores, 2017.

FREIRE, Paulo. Pedagogia da Autonomia: saberes necessários à prática educativa. São Paulo: Paz e Terra, 1996.

FOGARTY, R. Problem-based learning: a collection of articles. Arligton Heights: Skylight. 1998.

GIBBS, Graham. Análise de dados qualitativos. Tradução Roberto Cataldo. Porto Alegre: Artmed, 2009.

GLASGOW, N.A. New curriculum for new times: a guide student-centered, problem-based learning. Thousand Oaks: Corwin Press, 1997. 
GUIMARÃES, L. A. R. O aluno e a sala de aula virtual. In: LITTO, F. M.; FORMIGA, M. (Orgs.). Educação a Distância: o estado da arte. 2. ed. São Paulo: Pearson Education do Brasil, 2012. vol. 2. p. 126-133.

HEW, K.F.; CHEUNG, W.S. Using blended learning: Evidence-Based Pratices. Springer Singapore Heidelberg New York Dordrecht London. 2014.

HORN, Michael B.;STAKER, Heather. Blended: usando a inovação disruptiva para aprimorar a educação. Tradução: Maria Cristina Gularte Monteiro; revisão técnica: Adolfo Tanzi Neto, Lilian Bacich. Porto Alegre: Penso, 2015.

KNOWLES, Malcolm S. Self-directed learing: a guide for learners and teachers. U.S.A, Cambridge Adult Education. Prentice Hall Regents, 1975.

KNOWLES, Malcolm S. The Modern Practice of Adult Education: From Pedagogy to Andragogy. Cambridge Book Co, 1990.

KNOWLES, Malcolm S. The adult learner. Elsevier, USA, $6^{\mathrm{a}}$ edition, 2005.

LIMA, Jamile; SILVA, Cláudia; PAIVA, Clotilde. Autonomia em educação a distância: relatos a partir da prática de tutoria na disciplina fundamentos psicológicos da educação em dois cursos de licenciatura da UFPBVIRTUAL. 2010. Disponível em: http://www.abed.org.br/congresso2010/cd/352010000839.pdf . Acesso em: 10 jan. 2018.

LINDEMAN, Eduard C. The Meaning of Adult Education. New York, New Republic, 1926.

MANOVICH, Lev. El lenguage de los nuevos médios de comunicación: La imagen em La era digital. Tradução de Óscar Fontrodona. Barcelona: Paidós, 2005.

MATURANA, R. Humberto. Cognição, ciência e vida cotidiana. Organização e tradução Cristina Magroe Victor Paredes. Belo Horizonte: Editora UFMG, 2001. Disponível em: http://projetosntenoite.pbworks.com/w/file/fetch/57862773/Humberto\%20Maturana\%2020Cogni\%C3\%A7\%C3\%A3o,\%20Ci\%C3\%AAncia\%20e\%20Vida\%20Cotidiana.pdf\%20. Acesso em: 03 abr. 2017.

MOORE, M. G.; KEARSLEY, G. Educação a distância: uma visão integrada. Tradução Roberto Galman. São Paulo: Cengage Learning, 2008.

MORAN, José M. A educação que desejamos: novos desafios e como chegar lá. Campinas, SP: Papirus, 2012.

MORAN, José M. Mudando a educação com metodologias ativas. Coleção Mídias Contemporâneas. Convergências Midiáticas, Educação e Cidadania: aproximações jovens, v. 2, n. 1, p. 15-33, 2015. Disponível em: http://www2.eca.usp.br/moran/wpcontent/uploads/2013/12/mudando moran.pdf. Acesso em: 17 out. 2017. 
MORIN, E. Introdução ao pensamento complexo. Porto Alegre: Sulina, 2005.

MUSACCHIO, Cláudio de. Sociedade da Informação X Sociedade do Conhecimento. 2014. Disponível em: https://www.baguete.com.br/colunas/claudio-demusacchio/26/07/2014/sociedade-da-informacao-X-sociedade-do-conhecimento . Acesso em: 02 maio 2018.

OECD (Organization for Economic Co-operation and Development). E-Learning in Higher Education in Latin America. Paris: Development Centre Studies/OECD Publishing, 2015. Disponível em: http://dx.doi.org/10.1787/9789264209992-en . Acesso em: 02 abr. 2018.

PIAGET, Jean. Biologia e Conhecimento. 2. ed. Vozes: Petrópolis, 1996.

PIAGET, Jean. O diálogo com a criança e o desenvolvimento do raciocínio. São Paulo: Scipione, 1997.

PRETI, Oreste; NEDER, Maria Lúcia Cavalli; et al. Educação a Distância: sobre discursos e práticas. Brasília: Líber Livro Editora, 2005.

RIBEIRO, Luis Roberto de C. A aprendizagem baseada em problemas (PBL): uma implementação na educação em engenharia na voz dos atores. 2005. Tese (Doutorado em Educação) - Universidade Federal de São Carlos, São Carlos, 2005. Disponível em: https://repositorio.ufscar.br/bitstream/handle/ufscar/2353/TeseLRCR.pdf?sequence . Acesso em: 03 mai. 2018.

SARAVALI, Eliane G. A Psicopedagogia na Educação Superior: Contribuições da Teoria Piagetiana. Revista Psicopedagogia, v. 22, n. 69, p. 243-253, 2005. Disponível em: http://www.revistapsicopedagogia.com.br/detalhes/420/a-psicopedagogia-na-educacaosuperior--contribuicoes-da-teoria-piagetiana. Acesso em: 03 maio 2018.

SERAFINI, Alessandra M. dos S. A autonomia do aluno no contexto da educação a distância. Revista Educação em foco. Juiz de fora, v.17, n.2, p. 61-82. 2012. Disponível em: http://www.ufjf.br/revistaedufoco/files/2013/05/artigo-031.pdf . Acesso em: 04 abr. 2017.

SIEMENS, George. Connectivism: A Learning Theory for the Digital Age. 2005. Disponível em http://www.itdl.org/journal/jan 05/article01.htm . Acesso em: 20 jul. 2017.

SILVA, Daniela. A negociação pedagógica na aprendizagem autodirigida. In: VIEIRA, Flávia (Org.). Quando os professores investigam a pedagogia, em busca de uma educação mais democrática. Portugal: Edições Pedagogo, 2014. p. 103-143.

VERENIKINA, Irina M. Vygotsky in Twenty-first-century reserach. 2010. Disponível em: https://ro.uow.edu.au/cgi/viewcontent.cgi?referer=https://www.google.com/\&httpsredir=1\&ar $\underline{\text { ticle}=2337 \& a m p ; c o n t e x t=e d u p a p e r s}$. Acesso em: 29 jan. 2018. 
VIANA, Maria Aparecida P. Formação em serviço de professores iniciantes na educação superior e suas implicações na prática pedagógica. 2013. Tese (Doutorado em Educação) Pontifícia Universidade Católica de São Paulo (PUC-SP), São Paulo, 2013. Disponível em: https://tede2.pucsp.br/handle/handle/9709. Acesso em: 04 jul. 2014.

VIANA, Maria Aparecida; ALVES, Maria Dolores; SANTOS, Vera Lucia. Práticas Integradoras e Inclusivas no Ambiente Virtual de Ensino e Aprendizagem. IV Seminário WEB Currículo, PUC-SP. 2015. Pág. 1000 - 1007. Disponível em: http://www.pucsp.br/webcurriculo/edicoes_anteriores/2015/downloads/anais/anais_ivwebcurriculo 2015.pdf . Acesso em: 20 ago. 2017.

VIEIRA, Flávia. Autonomia na Aprendizagem da Língua Estrangeira. Centro de Estudos em Educação e Psicologia, Instituto de Educação e Psicologia. Universidad do Minho. Braga, 1998.

VYGOTSKY, Lev S. Mind in society: The development of higher psychological processes. Harvard University Press, 1978.

VYGOTSKY, Lev S. A formação social da mente. São Paulo: Martins Fontes, 1984.

\section{NOTAS}

${ }^{1}$ capacidade de absorver e trabalhar ativamente com uma determinada quantidade de informação proveniente de várias fontes, incluindo visual e auditiva.

${ }^{2}$ pessoas trazem experiências diferentes, ou conhecimento prévio, para cada experiência de aprendizagem, afetando o modo como apreenderão o conceito.

${ }^{3}$ São materiais de ensino, aprendizado e pesquisa, fixados em qualquer suporte ou mídia, que estejam sob domínio público ou licenciados de maneira aberta, permitindo que sejam utilizados ou adaptados por terceiros.

${ }^{4}$ Ela pressupõe que o comportamento de uma determinada pessoa é o resultado de leis aplicáveis a todos.

5 Criada em 1932, pelo psicólogo norte-americano Rensis Likert, a Escala Likert é uma escala de resposta psicométrica utilizada na maioria das vezes em pesquisas de opinião de clientes. Sendo uma das principais KPI's (Key Performance Indicator) de pesquisas do mundo, a escala é um dos indicadores mais antigos e tradicionais.

Enviado em: 06/09/2018

Aprovado em: 20/08/2019 